\title{
The warrior within: Fortifying mental health in the COVID-19 pandemic
}

\author{
Janet A. Young ${ }^{\mathrm{a}}$ \& Alan J. Pearce ${ }^{\mathrm{a}}$ \\ ${ }^{a}$ Victoria University, Melbourne, Australia.
}

\section{ABSTRACT}

There is growing evidence of the impact of COVID-19 on the mental health of individuals throughout the world. Coaches are not immune from this risk as they continue to see their livelihoods affected with closures and restrictions. This paper examines what coaches can do to mitigate the mental health consequences of the COVID-19 crisis. A number of key strategies are put forward for coaches to consider in preparation of a 'new normal'.

\author{
Key words: COVID-19, mental, \\ coach, health. \\ Received: 20 April 2020 \\ Accepted: 10 June 2020 \\ Corresponding author: Janet $A$. \\ Young, First Year College, \\ Victoria University, Melbourne, \\ Australia. Email: \\ janet.young@vu.edu.au
}

\section{INTRODUCTION}

"In the midst of chaos, there is also opportunity" (Sun Tsu)

2020 will long be remembered for the massive upheaval from the COVID-19 pandemic. Health, social and economic shocks of the pandemic continue to reverberate around the world with no immediate end in sight (World Health Organisation [WHO], 2020). As we try to comprehend the enormity of recent events, a striking feature about COVID-19 has been the speed and exponential nature of the pandemic that has crippled and enveloped world economies and communities (Hooper, 2020). The scale of the repercussions has been breath-taking and cautions us against believing that a reversion to 'what was' is possible.

Beyond the immediate physical health crisis, the upheaval caused by COVID-19 is having a profound effect on mental health (Holmes et al., 2020). Coaches are not immune from this psychological impact. It is therefore opportune to examine mental health as it relates to the COVID-19 crisis what are the key issues and how might coaches best equip themselves to successfully transition to a 'new normal'?

For the purposes of this paper we adopt the definition of 'mental health' proposed by the WHO (2018) namely, "a state of well-being in which an individual realizes his or her own abilities, can cope with the normal stresses of life, can work productively and is able to make a contribution to his or her community". To highlight the critical importance of mental health, WHO contends that mental health is an integral and essential component of the broader concept of 'health', being "a state of complete physical, mental and social well-being".

Effect of COVID-19 on mental health

Given the gravity of, and uncertainty surrounding, the COVID-19 pandemic it is natural for a range of intense negative emotions to exacerbate, such as fear and anxiety, anger, confusion and distress (Koh et al., 2020). These emotions are driven by a myriad of stressors (e.g., financial hardship; fear of infection, dying and losing family and loved ones; conflicting and negative reports about the virus; social isolation; loneliness) that were observed in precious viral outbreaks including SARS and MERS (Holmes et al, , 2020; Koh et al., 2020; United Nations [UN], 2020).

The evidence to date from national surveys confirms widespread psychological distress in COVID-19 affected populations (UN, 2020). The concern here is that the adverse emotional responses to the pandemic are closely associated with depression, self-harm and suicide attempts across the lifespan (Holmes et al., 2020). In the short term, individuals may resort to negative ways of coping including use of drugs, alcohol and online gaming (UN, 2020). In summary, COVID-19 is emotionally challenging for everyone, especially 
for individuals who are already at risk (e.g., those suffering from depression). Dealing with additional uncertainty, volatility, ambiguity, disruption and potential danger than previously can take a heavy toll.

\section{Unique circumstances of COVID-19}

To further appreciate the emotional responses to COVID-19 reported above, it may be helpful to reflect on the current gaps in scientific knowledge about the virus. Whilst much has been discovered about the virus since it was first reported in the media in January 2020, much remains unknown and needs to be understood to minimise the mystery, fear and uncertainty that fuel mental health issues for many.

Worries and uncertainties about a pandemic are common however COVID-19 is proving unique and extremely challenging. Calling for a collective global response, the New York Times (2020) recently identified what we do not yet know about the virus: how many people have been infected; the amount of time it takes to make you sick; why some people get so much sicker than others; the role of children in spreading the virus; when or where it started spreading and how long you will be immune after infection. At the same time as these questions challenge the scientific communities, so too does the global race for the development of a safe and effective vaccine.

What coaches can do to mitigate the mental health consequences of COVID-19

Coaches can take a pro-active approach to get to the other side of the COVID-19 crisis, equipped with enhanced or new capabilities to enjoy and embrace the 'new world' that undoubtedly will follow. To do so, coaches might consider adopting some of the strategies that were recently reported to build, and strengthen, resilience (Young, 2014). In the prevailing pandemic, coaches may find these strategies helpful to effectively adapt to the adversity and disconcerting changes surrounding COVID-19.

In addition, coaches might consider the following strategies that address the stressors of mental health cited above. These strategies are adapted from Csikszentmihalyi's (1990) research on happiness and the COVID-19 literature from leading international organisations (e.g., UN, 2020; WHO, 2020). The key here is for coaches to select and adopt strategies that meet their individual needs and circumstances. Strategies for consideration include:

\section{Commit to a meaningful purpose of your choice}

We have to know there is a desired destination to successfully weather the tumultuous buffering many of us have experienced/are experiencing. With a clear and meaningful purpose, we can get up again to face the next inevitable setback, challenge or difficulty, knowing there is a bright light on the other side of the pandemic. Having such a purpose gives us energy and resolve to keep going even when things look most daunting.

To start this process, you should create a realistic goal that is critically important to you; one which will motivate and excite you. Your goal might be related to your work, family or personal fitness and well-being. An example of a workrelated goal might be to retain, and then grow, the number of children in your coaching sessions prior to the COVID-19 pandemic by $20 \%$ before the end of 2021 .

With an overall destination guiding you, it is then easier to ensure that, in some way, each day is a step forward and progress is being made. Keep to a structure to your day and week and go one day at a time. For example, given the goal cited above, contacting players, identifying new players, researching, updating and creating safe and inclusive lesson plans and activities can all contribute to successfully reaching your final chosen destination.

Be flexible in the avalanche of change

The COVID-19 upheaval reminds us that we can never be quite sure what is around the corner so we need to be flexible, nimble and ready to adapt. Now is a good time to audit your coaching practices and procedures. Can they be readily adapted when circumstances call for it? Are you willing, and able, to embrace new ways of doing business? Flexibility is clearly essential to navigate the ebbs and flow of the on-going COVID-19 disruptions. So, take your time to pause, reflect, deliberate, consider and evaluate possibilities and then choose wisely. Know you may need to follow this process often given the ever-changing events of this year.

Prioritise fitness, fun activities and social connections

If you are going to reach your destination (as described above) you need to be in peak mental and physical condition. A good starting point is to acknowledge the COVID-19 crisis for what it is (e.g., alarming) and it is normal to feel anxious and stressed. Remind yourself that, rather than really being 'isolated', we are all in this together! The crisis is temporary and solutions will be found.

In the meantime, you can take good care of yourself, ensuring that you engage in pleasurable activities (e.g., painting, cooking) in your free-time and allow your brain to disconnect and recharge. Go for a daily walk or run. Find time to reconnect with nature observing the trees, weather or clouds for example as this can have considerable restorative benefits. Complementing an exercise regime, attend to your eating, drinking and sleep. Now is the perfect 
time to pamper yourself with a new or revised fun fitness/activity regime.

Social connections are still important, and perhaps more so, in times of physical distancing and isolation at home. Staying in touch is relatively easy to do through phone calls, text messages, video chat and social media. Keep checking in with friends, family, other coaches and support persons. Staying connected will help keep your spirits up, as will knowing you may be supporting others who might be struggling.

Take control of personal hygiene to best protect you and others

It is useless to worry about things you cannot change. What you can, and should, control is protecting yourself and others from the virus as best you can. This involves adopting personal protective practices of hand-washing, not touching the T-zone of the face and social or physical distancing. This definitely requires mindful attention to what one previously unconsciously might have done (e.g., freely touching surfaces around the court and training facilities).

Importantly, you have a duty of care to those who you coach and attend your sessions to protect their health and wellbeing. Safe practices, and communication of these, are key so let everyone know how you will be running sessions, activities and competitions to comply with best health practices and regulations. For example, how many players will be on the court at any time; should players bring their own drink bottles rather than use the drink fountain etc). Your National Association and the International Tennis Federation (https://www.itftennis.com/media/3446/returnto-tennis-guidelines-eng.pdf) can provide you with ideas and resources to provide safe sessions during these extraordinary times. Do not hesitate to stay connected with these organisations.

\section{Get facts to avoid the dangers of coronavirus 'infodemic'}

Misinformation can spread fear, anxiety and panic, so get the facts about COVID-19. This is especially important if you are a coach with staff who report to you. Talk to your team regularly to make sure that they have appropriate, accurate, clear and up-to-date information. To keep informed with credible facts you may wish to access the WHO (https://www.who.int/), UN (https://www.un.org/en/), the International Federation of the Red Cross (https://www.ifrc.org/) or UNICEF (https://www.unicef.org/) websites and your country's national authority on health.

In this context it is most beneficial to focus on the 'positive' versus more distressing facts. A sense of hope needs to replace a narrative of fear and helplessness. This is aided if, for example, you focus on the number of recoveries (versus deaths) and avoid stigmatising language in your communications that attaches ethnicity or region to the virus or blaming persons for transmission.

\section{Find 'Silver Linings'}

As difficult as it may sound, there are 'silver linings' to every catastrophe. Whilst these 'silver linings' are likely to be extremely thin compared with the scale of devastation of COVID-19, try to find them. Has COVID-19 given you renewed appreciation of family, friends, health, nature and coaching for example? Has it been a time for reflection, personal growth, creativity and learning new skills? Be grateful for these positives that may well have remained undiscovered had it not been for the COVID-19 upheaval.

\section{CONCLUSION}

COVID-19 is an unprecedented medical, human and economic crisis. The psychological impact on individuals worldwide is not to be under-estimated in these times of uncertainty, volatility and potential danger. Coaches around the world have had their livelihoods 'turned up-side-down' with work terminated, reduced, put on hold or modified to comply with new health guidelines and regulations. There is a call to action for coaches to rise to these challenges and take check of their mental health. It is hoped that this paper assists in the process so that, when coaches exit the crisis, they do so with enhanced or new capabilities to embrace and thrive in what will be a new beginning. Most importantly, coaches should not hesitate to get professional help if required along this journey.

\section{REFERENCES}

Csikszentmihalyi, M. (1990). Flow: The psychology of optimal experience. Harper \& Rowe.

Holmes, E. A., O'Connor, R. C., Perry, V. H., Tracey, I., Wessely, S., Arseneault, L., Ballard, C., Christensen, H., Cohen Silver, R., Everall, I., Ford, T., John, A., Kabir, T., King, K., Madan, I., Michie, S., Przybylski, A. K., Shafran, R., Sweeney, A., ... Bullmore, E. (2020). Multidisciplinary research priorities for the COVID-19 pandemic: a call for action for mental health science. The Lancet Psychiatry, 7, 547-560, https://doi.org/10.1016/S2215-0366(20)30168-1

Hooper, N., \& Southwood, J. (2020, May). What happens next? Company Director, 36(4) 16-19.

Inter-Agency Standing Committee (2020). Interim briefing note addressing mental health and psychosocial aspects of COVID-19 outbreak. https:// interagencystandingcommittee.org/other/ interim-briefing-note-addressing-mentalhealth-andpsychosocial-aspects-covid-19- outbreak (accessed March 24, 2020).

Koh, C., Lee, L., Lo, C., Wong, C., Yap, J. (2020). A socio-psychological perspective. World Economic Forum. http://www3.weforum.org/docs/WEF Challenges and Opportunit ies Post COVID 19.pdf

The New York Times. (2020, June 2). After six months, important 
mysteries about coronavirus endure.

https://www.nytimes.com/2020/06/01/health/coronavirus-

mysteries.html? searchResultPosition $=1$

United Nations. (2020). United Nations policy brief: COVID-19 and the need for action on mental health.

https://www.un.org/sites/un2.un.org/files/un_policy_briefcovid and mental health final.pdf

World Health Organisation. (2018). Mental health: Strengthening our response. https://www.who.int/en/news-room/factsheets/detail/mental-health-strengthening-our-response

World Health Organisation. (2020). Mental health and psychosocial considerations during COVID-19 outbreak.

https://www.who.int/docs/ default-source/coronavirus/mentalhealthconsiderations.pdf

Young, J.A. (2014). Coach resilience: What it means, why it matters and how to build it. ITF Coaching and Sport Science Review, 63, 10-12.

RECOMMENDED ITF TENNIS ACADEMY CONTENT (CLICK BELOW)

\section{TTF Academy}

Copyright (c) 2020 Janet A. Young \& Alan J. Pearce

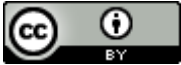

This text is under a Creative Commons BY 4.0 license

You are free to Share - copy and redistribute the material in any medium or format - and Adapt the content - remix, transform, and build upon the material for any purpose, even commercially under the following terms:

Attribution: You must give appropriate credit, provide a link to the license, and indicate if changes were made. You may do so in any reasonable manner, but not in any way that suggests the licensor endorses you or your use.

CCBY 4.0 license terms summary CCBY 4.0 license terms 